\title{
Structure and Reactivity of Rhodium(I) Carbonyl complexes as Model Nano-Wired Assemblies and Catalyst
}

\author{
P. P Mokolokolo, M. Schutte-Smith, A. Brink and A. Roodt \\ Department of Chemistry, University of the Free State, P.O. Box 339, Bloemfontein, 9300, South Africa; \\ mokolokolopp@ufs.ac.za
}

Square planar rhodium $(\mathrm{I})$ complexes of the type $\left[\mathrm{Rh}\left(\mathrm{L}, \mathrm{L}^{\prime}-\mathrm{Bid}\right)(\mathrm{CO})\left(\mathrm{PPX}_{3}\right)\right]$, where $\mathrm{L}, \mathrm{L}$ '-Bid $=$ monoanionic bidentate ligands and $\mathrm{PPX}_{3}$ are tertiary phosphine ligands, have been extensively investigated as potential catalyst precursors in different conversion reactions [1-5].

The main objective of this study is to use solution and solid state ${ }^{31} \mathrm{P}$ NMR spectroscopy in conjunction with X-ray crystallography to investigate the structure and reactivity relationship of the rhodium(I) complexes for potential application in catalysis.

A range of complexes of the type $\left[\mathrm{Rh}\left(\mathrm{L}, \mathrm{L}^{\prime}-\mathrm{Bid}\right)(\mathrm{CO})\left(\mathrm{PPX}_{3}\right)\right]$ with systematic manipulation of the steric and electronic properties were synthesized and characterized using IR, UV/Vis and NMR spectroscopy. These rhodium(I) complexes were obtained from the substitution of one carbonyl ligand in the complexes $\left[\mathrm{Rh}(\mathrm{L}, \mathrm{L}\right.$ '- $\left.\mathrm{Bid})(\mathrm{CO})_{2}\right]$, by simple stoichiometric reaction with monodentate tertiary phosphines. Correlations of different parameters such as the first-order coupling constant ${ }^{1} J_{\mathrm{Rh}-\mathrm{P}}$, chemical shift and the Rh-P bond-distances were evaluated in order to understand the coordination environment around the metal centre.

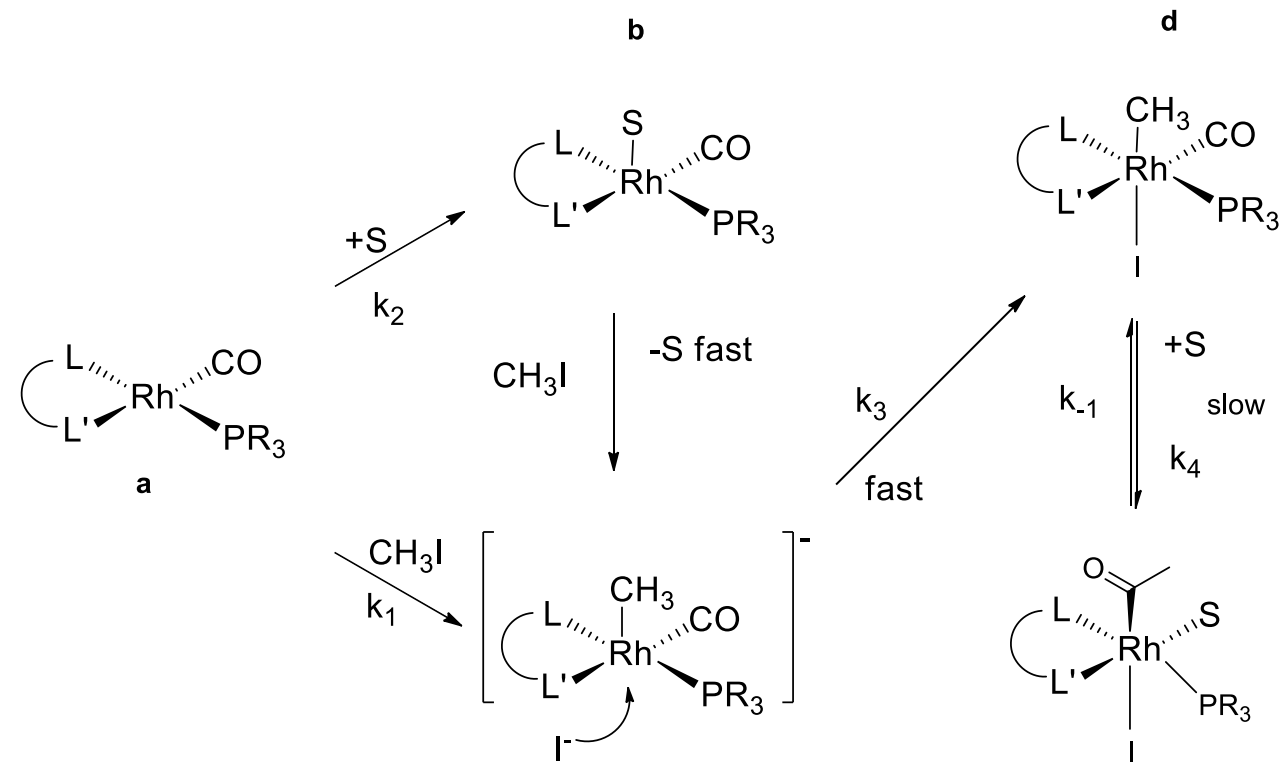

Figure 1: A representation of a typical scheme for the MeI oxidative addition the rhodium $\left[\mathrm{Rh}\left(\mathrm{L}, \mathrm{L}^{\prime}-\mathrm{Bid}\right)(\mathrm{CO})\left(\mathrm{PX}_{3}\right)\right], \mathrm{PX}_{3}=$ tertiary phosphine complexes. ${ }^{9} \mathrm{~S}=$ solvent.

[1] A. Roodt, H.G. Visser, A. Brink. Crystallogr. Rev. 17 (2011) 241-280.

[2] S. Warsink, F.G. Fessha, W. Purcell, J.A. Venter, J. Organomet. Chem. 726 (2013) 14-20.

[3] M. M. Conradie, J. Conradie, Dalton Trans. 40 (2011) 8226-8237.

[4] A. Brink, A. Roodt, G. Steyl, H.G. Visser, Dalton Trans. 39 (2010) 5572-5578.

[5] P.P Mokolokolo, A. Brink, M. Schutte-Smith, A. Roodt. J. Coord. Chem. 73 (2020) 2740.

Keywords: Rhodium(I) complexes, Metallophilic interactions, Catalysis 